Çukurova Üniversitesi Mühendislik Fakültesi Dergisi, 36(4), ss. 847-860, Aralık 2021

Cukurova University Journal of the Faculty of Engineering, 36(4), pp. 847-860, December 2021

\title{
Elektrokimyasal Depolama Yöntemi ile AISI 304 Çeliği Yüzeyine Biriktirilen Ni-B/TiB 2 Kompozit Kaplamaların Kristal Yapı ve Bazı Mekanik Özelliklerinin İncelenmesi
}

\author{
Ersin ÜNAL ${ }^{1}$ ORCID 0000-0002-3183-9592 \\ Abdulkadir YAŞAR ${ }^{* 2}$ ORCID 0000-0002-1548-2386 \\ İsmail Hakkı KARAHAN ${ }^{3}$ ORCID $0000-0002-8297-3521$
}

\author{
${ }^{1}$ Osmaniye Korkut Ata Üniversitesi, Mühendislik Fakültesi, Makine Mühendisliği Bölümü, \\ Osmaniye \\ ${ }^{2}$ Çukurova Üniversitesi, Ceyhan Mühendislik Fakültesi, Makine Mühendisliği Bölümü, Adana \\ ${ }^{3}$ Mustafa Kemal Üniversitesi, Fen Edebiyat Fakültesi, Fizik Bölümü, Hatay
}

Geliş tarihi: 17.05.2021 Kabul tarihi: 10.12.2021

Atıf şekli/ How to cite: ÜNAL, E., YAŞAR, A., KARAHAN, I.H., (2021). Elektrokimyasal Depolama Yöntemi ile AISI 304 Çeliği Yüzeyine Biriktirilen Ni-B/TiB 2 Kompozit Kaplamaların Kristal Yapı ve Bazı Mekanik Özelliklerinin Incelenmesi. Çukurova Üniversitesi, Mühendislik Fakültesi Dergisi, 36(4), 847860.

$\ddot{\mathbf{O} z}$

$\mathrm{Bu}$ çalışmada, Watts tipi nikel banyosunda $\mathrm{Ni}-\mathrm{B}$ alaşım anayapılı ve $\mathrm{TiB}_{2}$ mikro parçacık takviyeli kompozit kaplama, paslanmaz çelik altlık üzerine depolanmıştır. Elde edilen kompozit kaplamanın özellikleri saf nikel ve Ni-B alaşım kaplamalar ile mukayese edilerek incelenmiştir. Takviye parçacıkların etkisini belirlemek amacıyla kristal yapı, mikrosertlik, morfoloji ve aşınma dayanımı analizleri yapılmıştır. Elde edilen sonuçlara göre takviye parçacıkların, saf nikel ve Ni-B alaşımına göre kristal yapı üzerinde değişime neden olduğu görülmüştür. Ayrıca mikro $\mathrm{TiB}_{2}$ parçacıklar sertlikte de artışa sebep olmuştur. Parçacıklar mikro sertlikte, paslanmaz çeliğe göre \%225, saf nikele göre \%115 civarında artışa sebep olurken, Ni-B alaşımına kıyasla yaklaşık \%60 civarında bir artışla sonuçlanmıştır. Kompozit kaplamanın morfolojisinin de diğer kaplamalardan oldukça farklı olduğu, fakat genel olarak düzgün bir yüzeye sahip olduğu görülmüştür. Ayrıca, kompozit kaplamanın aşınma dayanımının saf nikel ve Ni-B alaşım kaplamalarına kıyasla daha iyi olduğu analiz sonuçlarından anlaşılmıştır.

Anahtar Kelimeler: Elektrodepolama, Kompozit kaplama, Mikrosertlik, Aşınma, Ni-B alaşım

\section{Investigation of Crystal Structure and Mechanical Properties of Electrochemically Deposited Ni-B/TiB 2 Composite Coatings}

\begin{abstract}
In this study, Ni-B alloy mainstructure and $\mathrm{TiB}_{2}$ micro particle supported composite coating was deposited in a Watts type nickel bath on a stainless steel substrate. The properties of the composite
\end{abstract}

*Sorumlu (Corresponding author) yazar: Abdulkadir YAŞAR, ayasar@cu.edu.tr 
Elektrokimyasal Depolama Yöntemi ile AISI 304 Çeliği Yüzeyine Biriktirilen Ni-B/TiB 2 Kompozit Kaplamaların Kristal Yapı ve Bazı Mekanik Özelliklerinin İncelenmesi

coating obtained were compared with pure nickel and Ni-B alloy coatings. Crystal structure, microhardness, morphology and wear resistance analysis were executed in order to determine the effect of reinforcement particles. According to the results, it was seen that reinforcement particles cause changes on the crystal structure compared to pure nickel and Ni-B alloy. In addition, micro $\mathrm{TiB}_{2}$ particles caused an increase in hardness. The particles resulted in an increase in micro hardness of about $225 \%$ compared to stainless steel and about $115 \%$ compared to pure nickel, while it resulted in an increase of about $60 \%$ compared to the Ni-B alloy. It has been observed that the morphology of the composite coating was also quite different from other coatings, but has a generally smooth surface. In addition, it was understood from the analysis results that the wear resistance of the composite coating was better compared to the pure nickel and Ni-B alloy coatings.

Keywords: Electrodeposition, Composite coating, Microhardness, Wear, Ni-B alloy

\section{GíRiș}

Yüksek mekanik dayanıkl1lık, iyi korozyon direnci ve maliyet etkinliği gibi olumlu özellikleri nedeniyle, mühendislik tasarımı nikel ve nikel alaşımlı kaplamalar yaklaşık yüzyıldır endüstride kullanılmaktadır [1-3]. Nikel esaslı kaplamalar, her sanayi sektörünün özel ihtiyaç ve talepleri doğrultusunda geliştirilmeye devam etmektedir. Örneğin, Ni-B kaplamalar otomotiv, havacılık ve kimya mühendisliği sektörlerinin yüksek korozyon, mekanik ve tribolojik direnç talepleri için kullanılabilmektedir [3-6]. Elektrolitik ve elektriksiz depolama teknikleri uygulama kolaylığ 1 ve çeşitliliği nedeniyle endüstride en çok tercih edilen tekniklerdir. Yüksek sıcaklıklara ve $\mathrm{pH}$ değerlerine ihtiyaç duyulması ve bu parametrelerin elektriksiz biriktirme için titiz bir şekilde uygulanması zorunluluğu nedeniyle, elektrodepolama metodu Ni-B kaplamaların biriktirilmesi için daha uygun görünmektedir [6-8].

Elektro-depolama metodunun tercih sebepleri arasında; hızlı yapılabilmesi, düşük maliyetli olması, kolay üretilmesi, saflığının yüksek olması, üretim parametrelerinin geniş bir aralıkta kontrol edilebilmesi, tekrar üretilebilirliği ve 1 sıl işleme ihtiyaç duyulmaması gibi özellikleri bulunmaktadır $[9,10]$. Alaşım kaplamalardan mekanik özellikler açısından belli bir seviyeye kadar olumlu sonuçlar alınabilmektedir, fakat seramik partiküllerle güçlendirilmiş kompozit kaplamalar, daha iyi özellikler elde etmek için umut verici bir ilerleme olarak görülmektedir [11].
Metal veya alaşım ana yapıya iyi dağılmış partiküller sadece mekanik özellikleri (sertlik, aşınma direnci) ve kimyasal kararlılığı (korozyon direnci, termal kararlılık) geliştirmekle kalmaz, aynı zamanda potansiyel uygulamalarını da genişletmektedir [12]. Son yıllarda Ni-B alaşımlı kompozit kaplamalarla ilgili birçok çalışma yapıldığı görülmektedir. $\mathrm{Bu}$ çalışmalara $\mathrm{Al}_{2} \mathrm{O}_{3}$ [11], hBN [3,13], $\mathrm{SiC}$ [14], $\mathrm{V}_{2} \mathrm{O}_{5}$ ve $\mathrm{ZrO}_{2}$ [15], $\mathrm{Tl}_{2} \mathrm{O}_{3}$ [16], AlN [17], elmas [18], TiC [19], YSZ [20], $\mathrm{Si}_{3} \mathrm{~N}_{4}$ [21] örnek olarak verilebilir.

Titanyum diborür $\left(\mathrm{TiB}_{2}\right)$ yüksek erime noktası $\left(2980{ }^{\circ} \mathrm{C}\right)$, yüksek sertlik (3350 $\left.\mathrm{Hv}\right)$, düşük elektrik direnci $(9 \Omega \mathrm{cm})$, yüksek korozyon direnci, yüksek 1slanabilirlik, daha iyi 1sıl şok direncine sahiptir. Ayrıca, yüksek mekanik ve aşınma direnci $\mathrm{TiB}_{2}$ ' ün üstün özelliklerindendir. $\mathrm{Bu}$ nedenle, türbin kanatları, yanma odaları, kimyasal reaktör kapları, kesici takımlar ve pompa çarkları gibi birçok uygulamalarda uygun bir kaplama malzemesidir [22-24]. $\mathrm{Bu}$ üstün özelliklere sahip $\mathrm{TiB}_{2}$ parçacıklarının kendisini birçok sektörde ispat etmiş Ni-B alaşım ana yapı ile birlikte imal edilmesiyle ortaya çıkacak kompozit kaplamanın özelliklerinin belirlenmesi hem bu alana yenilikler getirecek ve hem de önemli katkılar sunacaktır. Bu çalışmada, Ni-B alaşım ana yapı malzemesi, mikro boyuttaki titanyum diborür parçacıkları ile desteklenerek kompozit kaplama elde edilmiştir. Ana yapıya ilave edilen bu sert seramik partiküllerin mekanik ve kristal yapı özelliklerini nasıl etkilediği ile ilgili çeşitli analizler yapışmıştır. 


\section{MATERYAL VE METOT}

Kaplamalar AISI 304 paslanmaz çelik altlık üzerine elektrokimyasal depolama metodu ile geleneksel Watts tipi nikel banyosunda imal edilmiştir. Elektrokimyasal çalışmaların tümü $\mathrm{CH}$ instruments $608 \mathrm{E}$ model elektrokimyasal analiz cihazı ile gerçekleştirilmiştir. Katot olarak $4 \mathrm{~cm}^{2}$ alana sahip paslanmaz çelik kullanılırken, anot olarak platin malzemeli tel bir çubuk kullanılmıştır. Geleneksel 3 elektrotlu sistemde referans elektrot olarak doygun kalomel elektrot (SCE) kullanılmıştır. Katot, anot ve referans elektrotlar kaplama banyosu içine dikey olarak yerleştirilmişlerdir ve aralarında yaklaşık olarak 3'er $\mathrm{cm}$ boşluk bırakılmıştır.

Kaplama işlemine başlanmadan önce paslanmaz çelik altlıklar bir dizi hazırlık işleminden geçirilmiştir. Önce $4 \mathrm{~cm}^{2}$ alana sahip kaplama yapılacak paslanmaz çelik yüzeyi kalından inceye doğru zımpara kağıtları ile zımparalanmıştır. Daha sonra \%10 oranında hidroklorik asit $(\mathrm{HCl})$ ile karıştırılmış saf su içinde 1-2 dakika süresince dağlama işlemine tabi tutulmuş ve müteakiben saf su ile durulanarak oda sıcaklığında kurumaya bırakılmıștır.

Kaplama banyosunda nikel kaynağı olarak nikel sülfat hekza hidrat $\left(\mathrm{NiSO}_{4} \cdot 6 \mathrm{H}_{2} \mathrm{O}\right)$ ve nikel klorür hekza hidrat $\left(\mathrm{NiCl}_{2} \cdot 6 \mathrm{H}_{2} \mathrm{O}\right)$, bor kaynağ 1 olarak trimetilamin boran kompleksi (TMAB) kullanılmıştır. Kompozit kaplama elde etmek için banyo içine $2-5 \mu \mathrm{m}$ boyutunda titanyum diborür $\left(\mathrm{TiB}_{2}\right)$ toz parçacıkları ilave edilmiştir. Ayrıca elektrokimyasal banyoya yüzey aktifleştirici olarak sodyum dodesil sülfat (SDS) ve tane küçültücü ajan olarak ise sakarin ilave edilmiştir. Bunlara ilaveten $\mathrm{pH}$ düzenleyici ve kompleks yapıcı ajan olarak borik asit $\left(\mathrm{H}_{3} \mathrm{BO}_{3}\right)$ elektrolite belli oranda eklenmiştir. Tüm depolama işlemlerinde $50 \mathrm{~mA} / \mathrm{cm}^{2}$ akım yoğunluğu ve $\mathrm{pH} 4$ değeri kullanılmıştır. Banyo sıcaklığ 1 ise $43 \pm 1{ }^{\circ} \mathrm{C}$ civarlarında sabit tutulmaya çalışılmıştır. Depolama süresi ise $60 \mathrm{dk}$ olarak sabitlenmiştir.

Kompozit kaplama banyosunda olası parçacık topaklanmalarını önlemek amacıyla, depolama öncesi $30 \mathrm{dk}$ ultrasonik karıștırma yapılmıștır. Bu işlem Hielscher UP 200S marka ve model ultrasonik karıştırma cihazı ile gerçekleştirilmiş ve çevrim değeri 1, genlik değeri ise \%70 olarak ayarlanmıştır $(\sim 22 \mathrm{kHz})$. Ayrıca, kompozit kaplama depolanırken banyo manyetik karıştırıcı ile 200-300 dev/dk değerinde karıştırma işlemine tabi tutulmuştur. Çizelge 1'de elektrolit bileşenleri ve depolama parametreleri özet olarak sunulmuştur. Ayrıca, Çizelge 1'de kullanılan bütün kimyasal maddelerin yanlarında saflık dereceleri de belirtilmiştir. Depolama sonrasında numuneler saf su ile durulanmış ve oda sıcaklığında kurumaya bırakılmıştır. Mikro boyuttaki $\mathrm{TiB}_{2}$ parçacıkların toz boyutu ölçümleri Malvern Mastersizer 3000 tip cihaz kullanılarak gerçekleştirilmiştir. Olympus BX51 marka ve model cihaz ile de optik mikroskop görüntüleri elde edilmiştir. Mikro sertlik ölçümlerinde ise Future-TECH FM-700e marka ve model cihaz kullanılmıştır. Aşınma deneyleri için Turkyus marka POD\&HT\&WT model (Türkiye) aşınma analizi cihazı kullanılmıştır.

Üretilen saf nikel, Ni-B ve Ni-B/TiB 2 kaplamaların kristal yapılarının karakterize edilebilmesi için numunelerin XRD desenleri elde edilmiştir. X 1şını kırınım desenleri elde edilirken $2 \theta=0-100^{\circ}$ aralığında, $40 \mathrm{kV}$ ve $30 \mathrm{~mA}$ değerlerinde $\mathrm{CuK}_{\alpha}$ radyasyonu üreten PANalytical marka, Empyrean model XRD cihazı kullanılmıştır $(\lambda=1.5418 \AA)$.

Çizelge 1. Banyo bileşenleri ve depolama parametreleri

\begin{tabular}{|l|l|c|}
\hline Banyo bileşenleri & Görevi & Miktarı \\
\hline $\mathrm{NiSO}_{4} \cdot 6 \mathrm{H}_{2} \mathrm{O}$ (Nikel sülfat hekza hidrat) \%99,99 & Nikel kaynağ1 & $240 \mathrm{~g} / 1$ \\
\hline $\mathrm{NiCl}_{2} \cdot 6 \mathrm{H}_{2} \mathrm{O}$ (Nikel klorür hekza hidrat) \%98 & Nikel kaynağ1 & $45 \mathrm{~g} / \mathrm{l}$ \\
\hline $\mathrm{H}_{3} \mathrm{BO}_{3}$ (Borik asit) \%99,5 & Kompleks yapıc1 & $30 \mathrm{~g} / 1$ \\
\hline Trimetilamin boran kompleks (TMAB) \%97 & Bor kaynağ1 & $3 \mathrm{~g} / 1$ \\
\hline Titanyum diborür tozu ( $\left(\mathrm{TiB}_{2}\right) \% 99$ mikro boyutta & Takviye parçacık & $5 \mathrm{~g} / 1$ \\
\hline
\end{tabular}


Elektrokimyasal Depolama Yöntemi ile AISI 304 Çeliği Yüzeyine Biriktirilen Ni-B/TiB 2 Kompozit Kaplamaların Kristal Yapı ve Bazı Mekanik Özelliklerinin İncelenmesi

Çizelge 1 (Devam)

\begin{tabular}{|c|c|c|}
\hline Sodyum dodesil sülfat (SDS) \%99 & Yüzey aktifleştirici & $0,5 \mathrm{~g} / \mathrm{l}$ \\
\hline Sakarin $\% 98$ & Tane küçültücü & $2 \mathrm{~g} / \mathrm{l}$ \\
\hline \multicolumn{2}{|l|}{ Depolama parametreleri } & Değeri \\
\hline \multicolumn{2}{|l|}{ Akım yoğunluğu } & $50 \mathrm{~mA} / \mathrm{cm}^{2}$ \\
\hline \multicolumn{2}{|l|}{$\mathrm{pH}$} & 4 \\
\hline \multicolumn{2}{|l|}{ Sicaklık } & $43 \pm 1^{\circ} \mathrm{C}$ \\
\hline \multicolumn{2}{|l|}{ Süre } & $60 \mathrm{dk}$ \\
\hline \multirow{2}{*}{\multicolumn{2}{|c|}{ Banyo karıștırma hızı }} & $200-300 \mathrm{rpm}$ \\
\hline & & $30 \mathrm{dk}$ \\
\hline
\end{tabular}

\section{BULGULAR VE TARTIŞMA}

\subsection{Mikro Boyutlu $\mathbf{T i B}_{2}$ Takviye Parçacıkların Karakterizasyonu}

Mikro boyuttaki $\mathrm{TiB}_{2}$ parçacıkları için, tozların tedarik edildiği firmanın verdiği toz boyutu 2-5 $\mu \mathrm{m}$ aralığındadır. Mikro boyutlu takviye parçacıkların toz boyutu ölçümü sonucu elde edilen grafikler Şekil 1'de sunulmuştur. Şekil 1'deki veriler incelendiğinde toz boyutlarının yaklaşık $2,4 \mu \mathrm{m}$ ile $14 \mu \mathrm{m}$ aralığında değişen boyutlarda olduğu görülmektedir ve parçacıkların yaklaşık \%50'sinin toz boyutunun $5 \mu \mathrm{m}$ 'dan daha düşük değerlerde olduğu görülmektedir

Mikron boyutlu tozlarda topaklanma ve birbirine yapışma gibi nedenlerden dolayı $14 \mu \mathrm{m}$ 'a varan ölçüde toz boyutları elde edildiği ifade edilebilir.
Bunun yanında şekilde verilen grafik analiz edildiğinde $10 \mu \mathrm{m}$ 'dan büyük tozların miktarının, toplam toz miktarına göre çok daha az olduğu anlaşılmaktadır.

Mikro tozlar için firmanın verdiği toz boyutu 2-5 $\mu \mathrm{m}$ aralığındadır. Şekil 1'de mikro boyutlu parçacıkların toz boyutu ölçümü sonucu elde edilen grafikler verilmiştir. Şekil 1'deki ölçüm sonuçları incelendiğinde toz boyutlarının yaklaşık $2.4 \mu \mathrm{m}$ ile $14 \mu \mathrm{m}$ arasında değiştiği görülmektedir ve parçacıkların yaklaşık yarısının toz boyutunun $5 \mu \mathrm{m}$ 'dan daha küçük olduğu görülmektedir. Mikron boyutlu tozlarda topaklanma sonucu $14 \mu \mathrm{m}$ 'a varan ölçüde toz boyutları elde edildiği söylenebilir. Fakat şekildeki grafik incelendiğinde $10 \mu \mathrm{m}$ 'dan büyük tozların miktarının çok az olduğu görülmektedir.

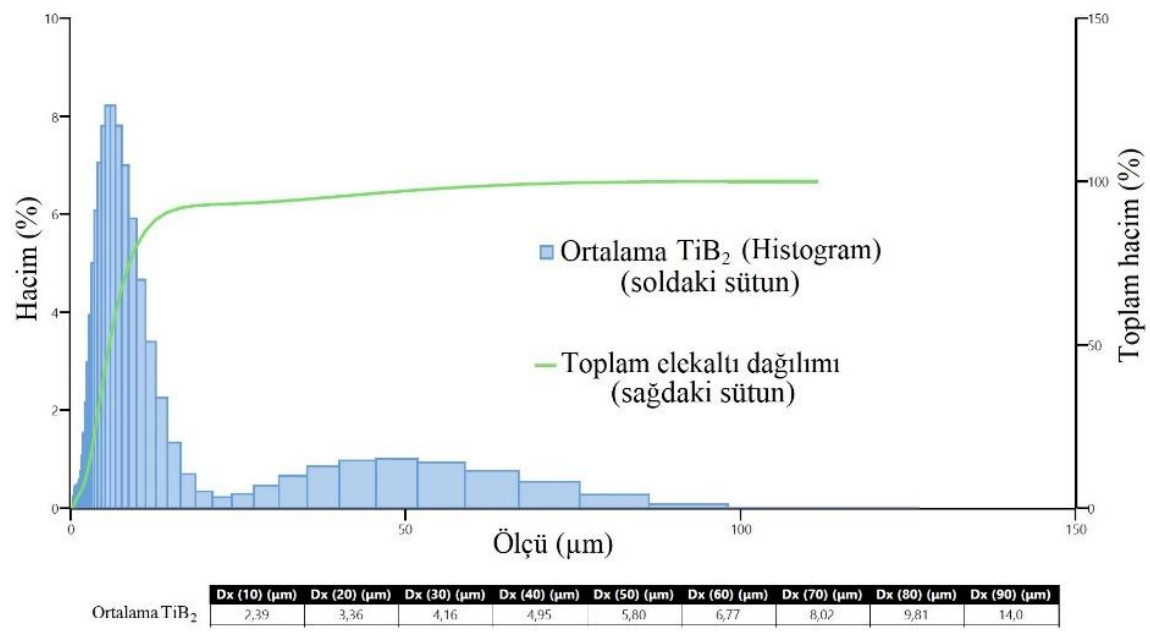

Şekil 1. Mikro boyutlu $\mathrm{TiB}_{2}$ parçacıkların toz boyutu ölçüm sonuçları 
Mikro boyuttaki $\mathrm{TiB}_{2}$ takviye parçacıklara ait XRD kırınım deseni Şekil 2'de verilmiştir. 44,2 derece civarında görülen (101), en şiddetli ana pik olmak üzere, bu pike (001), (100), (002), (110), (102), (111), (200), (201) ve (112) pikleri eşlik etmektedir. Takviye parçacık olarak kullandığımı bu $\mathrm{TiB}_{2}$ mikro tozlara ait XRD kırınım deseninin, literatürde $\mathrm{TiB}_{2}$ kullanılan çalışmalarda elde edilen XRD desenleri ile uyumlu olduğu görülmektedir [24-29]. Ayrica, Çizelge 2'de $\mathrm{TiB}_{2}$ tozlarına ait XRD deseninden elde edilen parametreler verilmiştir. $\mathrm{TiB}_{2}$ tozların tane büyüklüğü $70,8 \mathrm{~nm}$ olarak hesaplanmıştır. Şekil 2'de mikro boyutlu $\mathrm{TiB}_{2}$ takviye parçacıklara ait XRD kırınım sunulmuştur. En şiddetli pik, yani ana pik 44,2 derece civarında görülen (101) olarak göze çarpmaktadır, bu pike (001), (100), (002), (110), (102), (111), (200), (201) ve (112) pikleri eşlik etmektedir. Çalışmamızda ana yapıyı destek amaçlı parçacık olarak kullandığımız bu $\mathrm{TiB}_{2}$ mikro tozlara ait XRD kırınım deseni grafiğinin, literatürde diğer çalışmalarda kullanılan $\mathrm{TiB}_{2}$ parçacıklara ait XRD desenleri ile uyumlu olduğu görülmektedir [28,30-34]. $\mathrm{TiB}_{2}$ parçacıkların ortalama tane büyüklüğü Debye Scherrer denklemi [35] ile hesaplanmış ve $70,8 \mathrm{~nm}$ olarak elde edilmiştir.

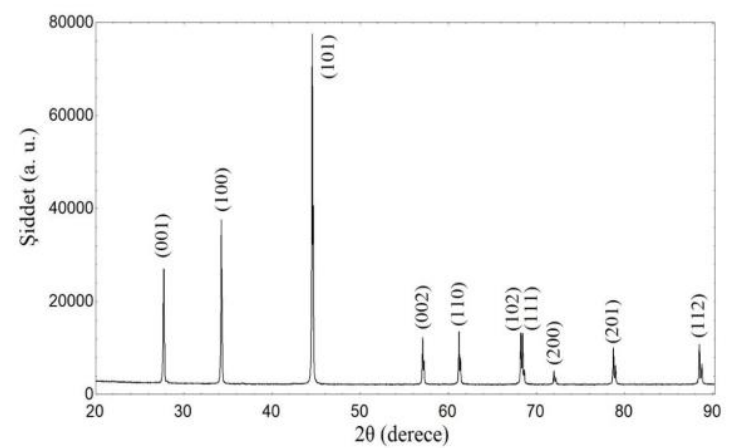

Şekil 2. Mikro boyuttaki $\mathrm{TiB}_{2}$ takviye parçacıkların XRD kırınım deseni

Çizelge 2. $\mathrm{TiB}_{2}$ takviye parçacıkların XRD deseninden elde edilen parametreler

\begin{tabular}{|c|c|c|c|c|c|}
\hline Numune & $2 \theta$ (derece) & $\begin{array}{l}\text { FWHM- } \beta \\
\text { (radyan) }\end{array}$ & $\begin{array}{l}\text { Ortalama kristal tane } \\
\text { büyüklüğü-D (nm) }\end{array}$ & Mikrogerilim- $\varepsilon$ & $\begin{array}{c}\text { Dislokasyon } \\
\text { yoğunluğu- } \delta \\
\left(\mathrm{nm}^{-2}\right)\end{array}$ \\
\hline $\mathrm{TiB}_{2}$ tozu & 44,5 & 0,00221 & 70,8 & $1,35 \times 10^{-3}$ & $0,2 \times 10^{-3}$ \\
\hline
\end{tabular}

\subsection{Depolama Banyolarının Kronopotansiyometri Analizleri}

Kronopotansiyometri grafikleri potansiyel değişiminin zamanın bir fonksiyonu olarak kaydedildiği eğrilerdir. Elde ettiğimiz kaplamalarda sabit akım uygulandığından dolayı, depolama esnasında potansiyel sürekli değişmektedir. Depolama yapmamıza imkân veren elektrokimyasal cihaz, sabit akımı hassas bir şekilde sağlayabilmek için anlık olarak potansiyel değerini düzenlemektedir. Kaplamanın yapıldığ elektrolitin cinsine ve ihtiva ettiği bileşenlere göre bu grafikler farklı seyirler izleyebilmektedirler. Depolama zamanı 3600 saniyedir. Şekil 3'te $\mathrm{Ni}-\mathrm{B} / \mathrm{TiB}_{2}$ kompozit kaplama ve karşılaştırma amacıyla saf nikel ve Ni-B alaşım kaplamalara ait kronopotansiyometri grafikleri bir arada sunulmuştur. Saf nikel depolanma potansiyeli -1.3 V civarlarında gerçekleşmiştir. Banyoya TMAB ilave edilmesiyle birlikte depolama potansiyelinde bir miktar artış olduğu gözlenmektedir. Fakat depolama sonlarına doğru Ni-B alaşım ve saf nikelin depolama potansiyellerinin birbirine yakın seyir izledikleri görülmektedir. Elektrokimyasal banyoya mikro boyuttaki $\mathrm{TiB}_{2}$ parçacıklarının ilave edilmesiyle birlikte depolama potansiyelinde önce ciddi bir artış olduğu, daha sonra bir miktar salınımla azalarak 1500. saniyeden sonra yatay bir seyir izlediği anlaşılmaktadır. Depolama başlangıcında $-2.2 \mathrm{~V}$ civarlarından, azala azala $-1.6 \mathrm{~V}$ civarlarına kadar gerilemiştir. Kompozit kaplama banyosunda saf nikel ve Ni-B alaşım kaplama banyolarına kıyasla nispeten daha yüksek bir depolama potansiyeli ile depolanmanın gerçekleştiği görülmektedir. Banyoya ilave edilen parçacıkların elektrolitin direncinde bir miktar yükselmeye sebep olmasında ötürü, potansiyel artışına neden olduğu düşünülmektedir. Ayrıca, sürüklenme yolu ile taşınan $\mathrm{TiB}_{2}$ parçacıklarının ortamda bulunmasından kaynaklanan bu potansiyel artışı, 
parçacıkların ana yapı ile birlikte kompozit olarak depolandığının da önemli bir verisi olarak görülebilir.

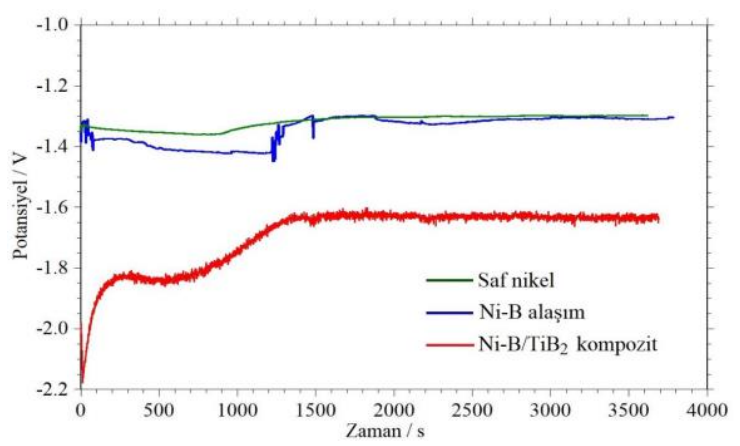

Şekil 3. Kaplama banyolarının kronopotansiyometri grafikleri

\subsection{Kaplamaların Kristal Yapı Analizleri}

Numunelerin ortalama kristal tane boyutu (D), mikrogerilim $(\varepsilon)$ ve dislokasyon yoğunluğu $(\delta)$ değerleri hesaplanırken aşağıda verilen formüllerden faydalanılmıştır [30-36] (Eşitlik 1).

$D=\frac{0,94 \lambda}{\beta \cos \theta}$

(1) numaralı Debye-Scherrer denkleminde $\lambda$ : $\mathrm{X}$-1şını dalga boyu, $\beta$ : ilgili pikin yarı maksimumdaki genişliğinin radyan cinsinden değeri (FWHM), $\theta$ : ise ilgili pikin Bragg yansıma açısıdır [36] (Eşitlik 1).

$\varepsilon=\frac{\beta}{4 \tan \theta}$

(2) numaralı denklem, mikrogerilim hesaplanmasında kullanılmıştır [30] (Eşitlik 2).

$\delta=\frac{1}{D^{2}}$

(3) numaralı denklem, dislokasyon yoğunluğu hesaplanmasında kullanılmıştır. Burada D: ortalama kristal tane boyunu ifade etmektedir [30, 33-35].
Şekil 4'te Ni-B/TiB 2 kompozit kaplamayla birlikte mukayese amaciyla saf nikel ve Ni-B alaşım kaplamaların XRD desenleri bir arada verilmiştir. Saf nikelin XRD deseni incelendiğinde $52^{\circ}$ civarlarında görülen (200) piki ana pik olmak üzere, bunun yanında (111), (220), (311) ve (222) nikele özgü piklerinin de XRD desenine yansıdığ1 görülmektedir. (220), (311) ve (222) piklerinin (200) ve (111) piklerine göre çok daha düşük şiddetlerde olduğu ifade edilebilir.

Ni-B alaşımının XRD desenine göz attığımızda, bor atomlarının kafes yapısına dahil olması ile birlikte $44,3^{\circ}$ civarlarındaki nikele özgü (111) piki haricinde diğer tüm piklerin kaybolduğu görülmektedir. Ayrıca, bu pikin şiddetinin de saf nikele nazaran epeyi bir miktar azaldığ anlaşılmaktadır. Elektrodepolanmış saf nikel ve Ni-B alaşım kaplamalarla ilgili literatürde de benzer XRD sonuçları elde edildiği görülmektedir [37-41]. Banyoya mikro boyutta $\mathrm{TiB}_{2}$ parçacıkların ilave edilmesi ile elde edilen kompozit kaplamanın XRD desenini incelediğimizde nikele özgü piklerin tekrar görünür hale geldiğini söyleyebiliriz. En dikkat çekici fark ise (111) ve (200) piklerinde görülmektedir. $\mathrm{Bu}$ piklerin şiddetleri saf nikele oranla ciddi miktarda azalmıştır ve en şiddetli ana pik kompozit kaplama için (111) pikidir. Kompozit kaplamada (111) pikinin şiddeti saf nikele göre azalmış görünürken, Ni-B alaşım kaplamaya göre artmış görünmektedir. Ana yapıya bor atomlarının ilavesinin XRD pik yüksekliklerinde azalmaya sebep olduğunu, yani yapıyı kristalli yapıdan amorfa doğru değiştirdiğini ifade edebiliriz. Fakat $\mathrm{TiB}_{2}$ parçacıklarının ana yapıya dahil olması ile birlikte, bor atomlarının kristal yapı üzerindeki etkisini azaltarak, tekrar XRD piklerinde artışa sebep olduğu ifade edilebilir.

Literatürde Ni-B ana fazı ile birlikte çalışılan diğer takviye seramik parçacıklarda da benzer sonuçlar elde edildiği görülmektedir $[11,13,15]$. Kompozit kaplamada (200) piki ise saf nikele göre ciddi miktarda azalmıştır, Ni-B kaplamada ise zaten bu pik hiç görünmemektedir. 
Çizelge 3'te saf nikel, Ni-B alaşım ve $\mathrm{Ni}-\mathrm{B} / \mathrm{TiB}_{2}$ kompozit kaplamaların XRD desenlerinden elde edilen parametreler verilmiştir. $\mathrm{Bu}$ değerler hesaplanırken en yüksek şiddete sahip XRD pikine ait değerler üzerinden hesaplamalar yapışmıştır. En önemli parametrelerden biri de ortalama kristal tane büyüklüğüdür. Saf nikelin kristal tane boyu 42,6 nm civarlarında hesaplanırken, Ni-B için bu değer çok ciddi derecede azalmış ve 8,7 nm civarlarında hesaplanmıştır. Bor elementinin nikel ana fazını kristalli bir yapıdan, amorf bir yapıya dönüştürdüğünü daha önce belirtmiştik. Aynı zamanda bor elementi ile alaşımlama, mikrogerilim ve dislokasyon yoğunluğu değerlerinde de saf nikele kıyasla artı̧̧a neden olmuştur. Bor elementinin nikel yüzey merkezli kübik (YMK) kristal kafes yapısı içinde ara yerleri işgal etmesiyle birlikte, nanokristalli Ni-B alaşımların, Ni YMK yapısı içinde bor atomlarını ihtiva eden katı bir çözelti olduğunu söyleyebiliriz. Yapıdaki bu değişimin mikrogerilim ve dislokasyon yoğunluğu değerlerinde artışa sebep olduğunu ifade etmek mümkündür [38]. Anayapının $\mathrm{TiB}_{2}$ parçacıklarla takviye edilmesi, ortalama kristal tane büyüklüğünde bir miktar artışa sebep olmuş ve $\mathrm{Ni}-\mathrm{B} / \mathrm{TiB}_{2}$ kompozit kaplama için bu değer $13,8 \mathrm{~nm}$ civarlarında hesaplanmıştır. $\mathrm{Bu}$ sonuca göre mikro $\mathrm{TiB}_{2}$ parçacıkların ana yapı içerisinde Ni-B alaşımı ile kıyas edildiğinde kristalleşmeyi desteklediğini ifade edebiliriz. Fakat saf nikele göre halen çok daha düşük miktarda bir tane boyutu değeri elde edildiği görülmektedir. Kompozit kaplama için mikrogerilim ve dislokasyon yoğunluğu değerleri Ni-B alaşımına göre bir miktar azalmış olduğu anlaşılmaktadır. Bu durumda iç yapıdaki gerilimin $\mathrm{Ni}-\mathrm{B}$ alaşımına göre biraz daha azaldığ 1 söylenebilir.

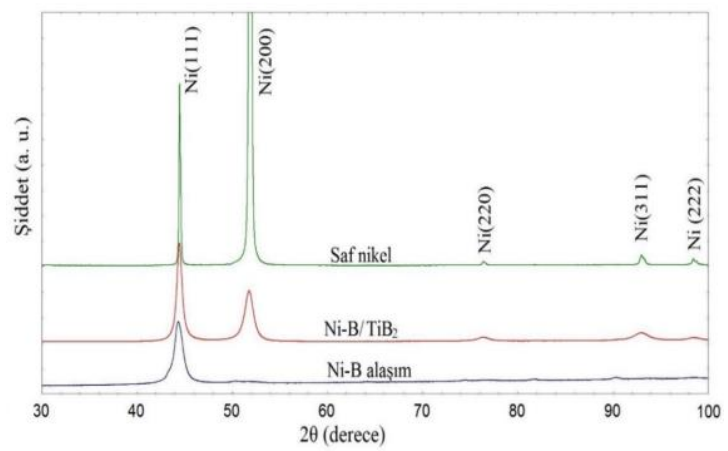

Şekil 4. Ni-B/TiB ${ }_{2}$ kompozit, Ni-B alaşım ve saf nikel kaplamaların XRD desenleri

Çizelge 3. Saf nikel, Ni-B alaşım ve Ni-B/TiB ${ }_{2}$ kompozit kaplamaların XRD desenlerinden elde edilen parametreler

\begin{tabular}{|c|c|c|c|c|c|}
\hline Numune & $\begin{array}{c}2 \theta \\
\text { (derece) }\end{array}$ & $\begin{array}{l}\text { FWHM- } \beta \\
\text { (radyan) }\end{array}$ & $\begin{array}{l}\text { Ortalama kristal tane } \\
\text { büyüklüğ̈ü-D }(\mathbf{n m})\end{array}$ & Mikrogerilim- $\varepsilon$ & $\begin{array}{c}\text { Dislokasyon } \\
\text { yoğunluğu- } \delta\left(\mathrm{nm}^{-2}\right)\end{array}$ \\
\hline Saf nikel & 51,8 & 0,00378 & 42,6 & $1,94 \times 10^{-3}$ & $0,551 \times 10^{-3}$ \\
\hline Ni-B & 44,3 & 0,01785 & 8,7 & $10,9 \times 10^{-3}$ & $13,2 \times 10^{-3}$ \\
\hline $\mathrm{Ni}-\mathrm{B} / \mathrm{TiB}_{2}$ & 44,4 & 0,01132 & 13,8 & $6,9 \times 10^{-3}$ & $5,2 \times 10^{-3}$ \\
\hline
\end{tabular}

\subsection{Kaplamaların Morfolojik Analizleri}

Şekil 5 ve 6'da Ni-B/TiB 2 kompozit kaplama ve mukayese amacıyla saf nikel ve Ni-B alaşım kaplamaların optik mikroskop görüntüleri verilmiştir. Şekil 5 'teki görüntüler 200 büyütme oranında, Şekil 6'daki görüntüler ise 500 büyütme oranında elde edilmiştir. Genel olarak üç farklı kaplamanın da gayet düzgün bir yüzeye sahip olduğu söylenebilir. Fakat yüzeye daha yakından bakıldığında saf nikel kaplamanın, diğer kaplamalara kıyasla daha pürüzlü bir morfolojiye sahip olduğu görülmektedir. Ni-B alaşım ve Ni$\mathrm{B} / \mathrm{TiB}_{2}$ kompozit kaplamanın yüzey görünümü saf nikel kaplamadan çok farklı görünmektedir. Ni-B alaşım ve kompozit kaplamanın yüzeyinde dairesel şekilli yapıların çok daha yoğun olduğu anlaşılmaktadır. Saf nikel kaplamada ise yükselti farklılıklarından kaynaklanan, belirsiz sekilli birtakım yapılardan oluşmuş piramidal şekilli bir yüzey görünümü olduğu görülmektedir. 
Elektrokimyasal Depolama Yöntemi ile AISI 304 Çeliği Yüzeyine Biriktirilen Ni-B/TiB ${ }_{2}$ Kompozit Kaplamaların Kristal Yapı ve Bazı Mekanik Özelliklerinin İncelenmesi
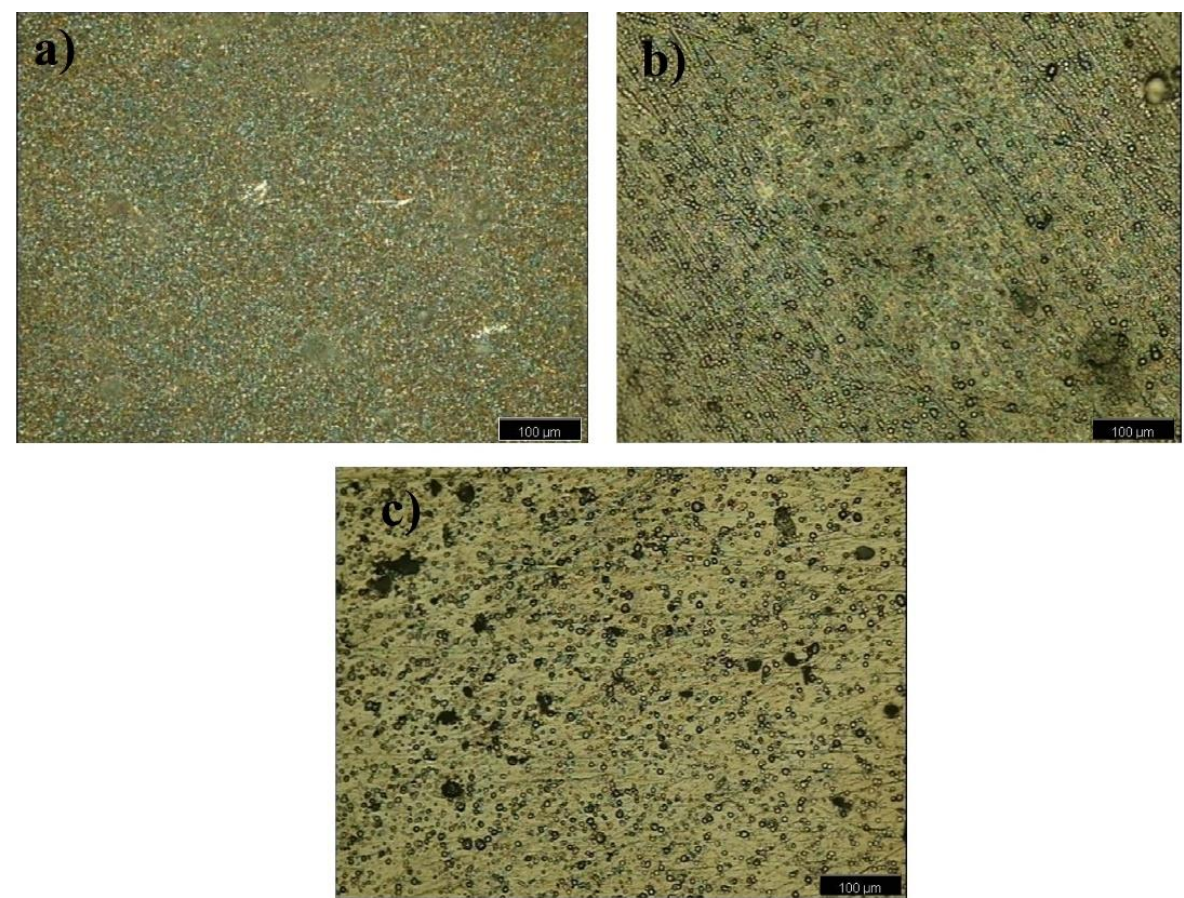

Şekil 5. Kaplamaların optik mikroskop görüntüleri a) saf nikel, b) Ni-B alaşım, c) Ni-B/TiB ${ }_{2}$ kompozit (200 büyütme oranında)
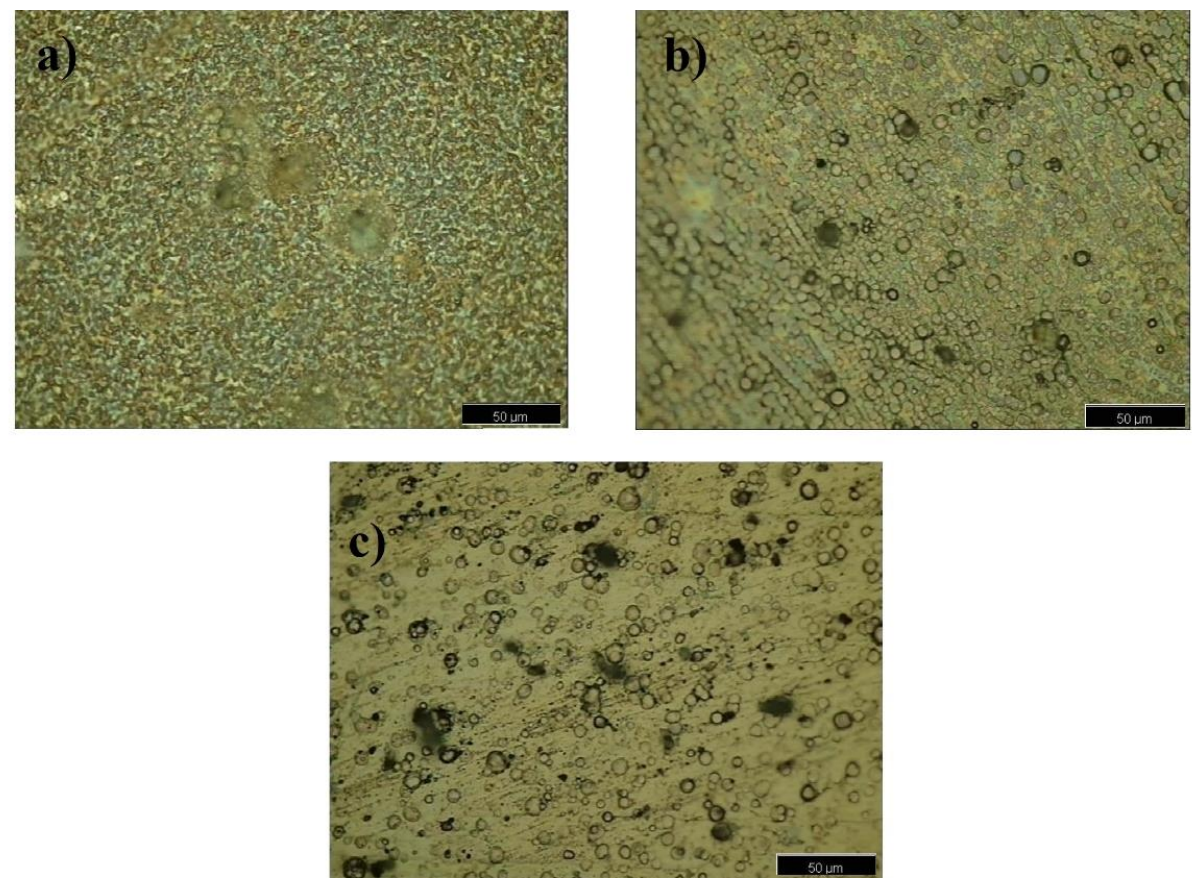

Şekil 6. Kaplamaların optik mikroskop görüntüleri a) saf nikel, b Ni-B alaşım, c) Ni-B/TiB ${ }_{2}$ kompozit (500 büyütme oranında) 


\subsection{Kaplamaların Mikrosertlik Analizi}

Mikro sertlik değerlerinin ölçümünde 500 g'llk yük numune üzerine $10 \mathrm{~s}$ boyunca uygulanmıştır. En az 10 farklı noktadan numune üzerinde ölçümler alınmış ve bu ölçümlerin aritmetik ortalaması alınarak mikro sertlik değeri bulunmuştur. Ortalamadan aşırı derecede sapan mikro sertlik değerleri numunenin genel ortalamasına katılmamıştır. Şekil 7'de Ni-B/TiB kompozit kaplamayla birlikte karşılaştırma amacıyla paslanmaz çelik altlık, saf nikel ve Ni-B alaşım kaplamanın mikrosertlik ölçüm sonuçları bir arada verilmiştir. Paslanmaz çelik altlığın sertliği 200 Hv civarlarında ölçülürken, saf nikelin sertlik değeri ise $300 \mathrm{Hv}$ civarlarında ölçülmüştür.

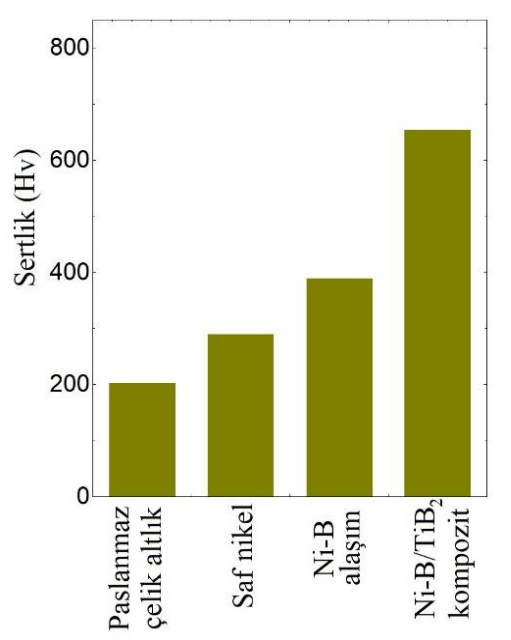

Şekil 7. Altlık ve kaplamaların mikrosertlik değerleri

Saf nikelin bor atomları ile alaşımlanması neticesinde elde edilen Ni-B alaşım kaplamanın sertliği ise $400 \mathrm{Hv}$ civarlarında ölçülmüştür. Ni-B alaşım ana yapının $\mathrm{TiB}_{2}$ ile takviye edilmesi ile elde edilen kompozit kaplamanın sertliği ise 650 Hv civarlarında elde edilmiştir. Bu durumda takviye parçacıklarla destek işlemi sertlikte paslanmaz çeliğe göre $\% 225$, saf nikele göre $\% 115$ civarında artışa sebep olurken, Ni-B alaşımına kıyasla yaklaşık $\% 60$ civarında bir artışla sonuçlanmıştır. Sertlikteki bu artış, Ni-B alaşımına parçacık takviyesi sebebiyle olup bu durum, literatürde Orowan dispersiyon sertleşmesi mekanizması ile açıklanmaktadır. Sert parçacıkların yapı içindeki varlığı çizgi kusurları (dislokasyon) hareketlerini engellemektedir ve çizgi kusurları pimleme etkisi, dağılmış parçacıkların dayanımını arttırma etkisine sebep olmaktadır. Hareket yörüngesinde bulunan parçacıkların yanından geçen bir çizgi kusuru için kritik şart, parçacıklar arasında bir yarım daire şeklinde kendisini bükmesidir. Sonrasında çizgi kusuru ilerlemekte ve çizgi kusuru düğümünü geride bırakmaktadır. Dolayısıyla, çözünmeyen parçacıkların yapıda bulunması, çizgi kusuru pimleme etkisine sebep olmakta ve böylece dayanım ve sertlikte artış meydana gelmektedir [11].

\subsection{Kaplamaların Aşınma Analizleri}

Saf nikel ve Ni-B/TiB 2 kompozit kaplamaların aşınma davranışlarını incelemek amacıyla $2 \mathrm{~N}$ yük altında ve $0,25 \mathrm{~m} / \mathrm{s}$ hızında gerçekleştirilmiştir. İz çapı $10 \mathrm{~mm}$ olarak ayarlanmış, deney oda sicaklığında gerçekleştirilmiş ve süresi $400 \mathrm{~s}$ ile sınırlandırılmıştır. Aşınma analizinde disk üzerinde bilye (ball on disk) yöntemi kullanılmış ve karşı malzeme olarak, yani bilye olarak $6 \mathrm{~mm}$ çapında paslanmaz çelik tercih edilmiștir. Ni-B alaşım kaplama aşırı iç gerginlikten dolayı altlığa tutunamadığı için aşınma analizi yapılamamıştır. Elde edilen bütün Ni-B alaşım numune kaplamalarda çatlaklar, pullanmalar, kavlama ve kıvrılmalar dolayısıyla dengeli bir zemin elde edilememiştir.

Şekil 8'de saf nikel ve $\mathrm{Ni}-\mathrm{B} / \mathrm{TiB}_{2}$ kompozit kaplamların sürtünme katsayısı grafikleri verilmiştir. Şekil 9'da ise numunelerin aşınma deneyi sonrası elde edilen aşınma izlerinin optik mikroskop görüntüleri verilmiștir. Çizelge 4 'te ise aşınma analizinden elde edilen veriler özet olarak sunulmuştur. Sürtünme katsayısı grafikleri ve Çizelge 4'te verilen ortalama sürtünme katsayısı verileri beraber değerlendirildiğinde kompozit kaplamanın saf nikele göre daha düşük sürtünme katsayısı değerleri sergilediği görülmektedir. Saf nikel için ortalama sürtünme katsayısı değeri 0,227 elde edilirken, kompozit kaplama için bu değer 0,187 elde edilmiştir. Kompozit kaplamanın $\mathrm{TiB}_{2}$ parçacıkları ile desteklenmesi sertliği artırmış ve 
Elektrokimyasal Depolama Yöntemi ile AISI 304 Çeliği Yüzeyine Biriktirilen Ni-B/TiB 2 Kompozit Kaplamaların Kristal Yapı ve Bazı Mekanik Özelliklerinin İncelenmesi

artan sertliğe ilaveten, ana yapı içerisindeki takviye parçacıklarında katkısıyla sürtünme katsayısında bir miktar azalmaya sebep olmuş olabilir. Şekil 8 a'da verilen grafikte deney süresi boyunca saf nikelin sürtünme katsayısı grafiği genel olarak kompozit kaplamaya kıyasla daha az salınımlı bir seyir izlemektedir. Aynı șekilde b'de gösterilen kompozit kaplamaya ait grafikte ilk başlarda sürtünme katsayısı çok düşük değerlerle başlamış ve ilerleyen sürelerle birlikte yüzeydeki kaygan tabakaların deforme olmasına müteakip artış göstermiştir. Sürtünme katsayısı grafiklerindeki bu yüksek salınıml seyir, aşınmanın yapışma ve kayma (stick-slip) hareketi yaparak gerçekleștiği izlenimini vermektedir. Yapışma esnasında sürtünme katsayısı önce belli bir maksimum değere kadar artı̧ göstermekte, müteakiben kopmayla birlikte ise sürtünme katsayısında ani düşüş meydana gelmektedir $[42,43]$.
Sekil 9'da verilen aşınma izleri incelendiğinde kompozit kaplamanın saf nikele oranla daha dar bir aşınma izine sahip olduğu anlaşılmaktadır. Saf nikelin aşınma iz genişliği yaklaşı olarak $400 \mu \mathrm{m}$ civarlarındayken, kompozit kaplamanın aşınma izi genişliği ise $280 \mu \mathrm{m}$ civarlarında ölçülmüştür. Aşınma deneyi parametreleri ve aşınma iz genişliğinden elde edilen aşınma hacim kaybı (V) değerleri Çizelge 4'te verilmiştir. Bu değerler aşınma iz genişliği ve bazı deney parametrelerini esas alan aşağıdaki verilen formülden hesaplanmıştır [44] (Eşitlik 4).

$$
V=2 \pi R\left[r^{2} \sin ^{-1} \frac{w}{2 r}-\frac{w}{4} \sqrt{\left(4 r^{2}-w^{2}\right)}\right]
$$

Burada $\mathrm{R}$ aşınma deneyi iz yarıçapı, $\mathrm{r}$ aşınma deneyinde kullanılan bilye yarıçapı, w ortalama aşınma iz genişliğidir.
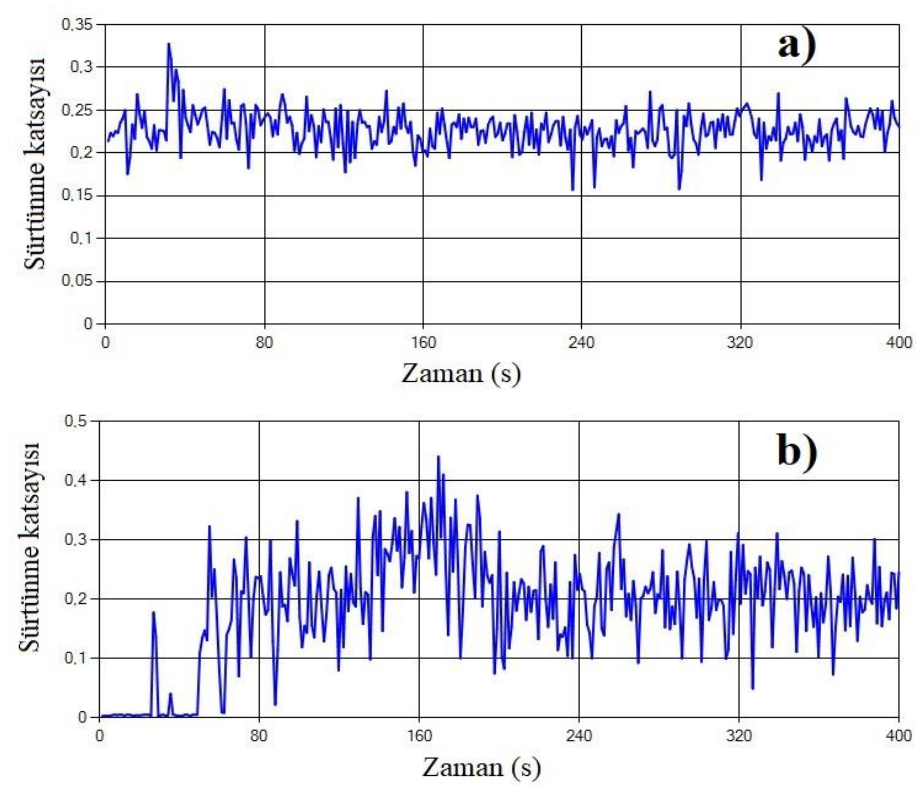

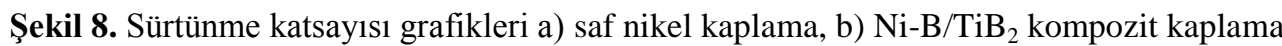

Saf nikel için aşınma hacim kaybı $0,04636 \mathrm{~mm}^{3}$ olarak hesaplanırken, kompozit kaplama için aşınma hacim kaybı $0,01915 \mathrm{~mm}^{3}$ olarak hesaplanmıştır. Şekil 9'daki aşınma izleri incelendiğinde saf nikel için plastik deformasyon aşınma mekanizmasının (adesiv) hakim olduğu görülmektedir. Bunun yanı sıra kompozit kaplamada ise mikro çizilme aşınma mekanizması şeklinde ifade edebileceğimiz abrasiv aşınma türünün hakim olduğu ifade edilebilir. Aşınma esnasında kopan sert parçacıklar iki metal arasında kalarak kazıma etkisi göstermekte ve abraziv 
aşınmaya sebep olabilmektedir. Abrasiv aşınmada keskin ve sert parçacıklar malzeme yüzeyinden mikron seviyesinde talaş kaldırabilmektedir. Bu
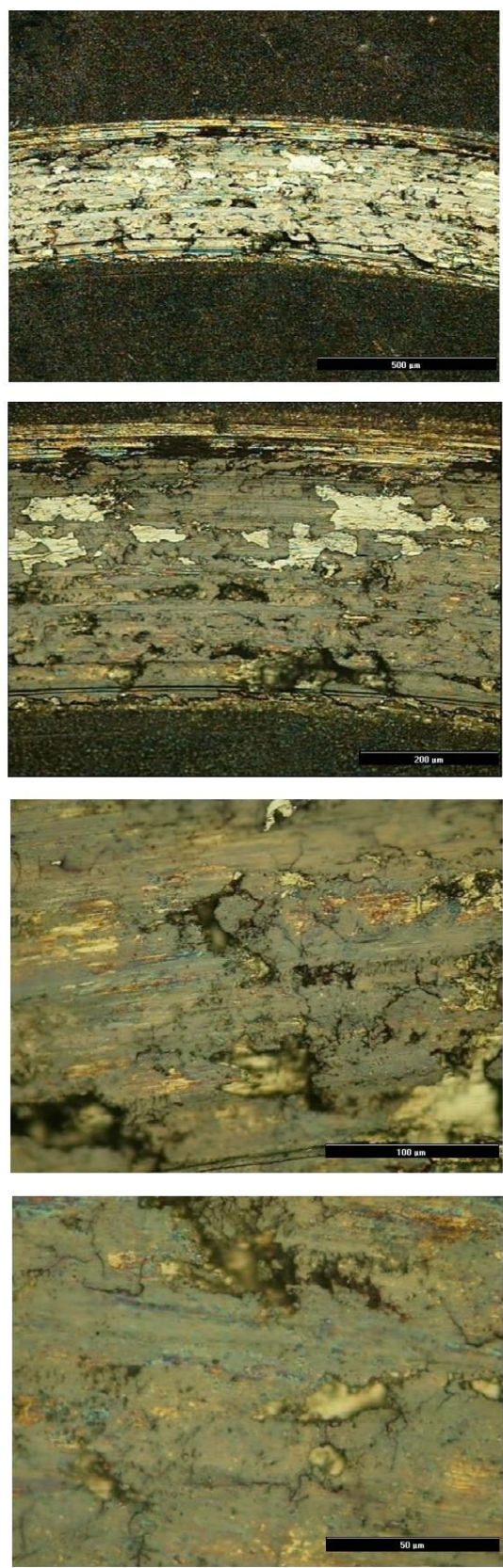

Saf nikel şekilde aşınan yüzeylerde mikron boyutunda çizikler oluşabilmektedir [45].
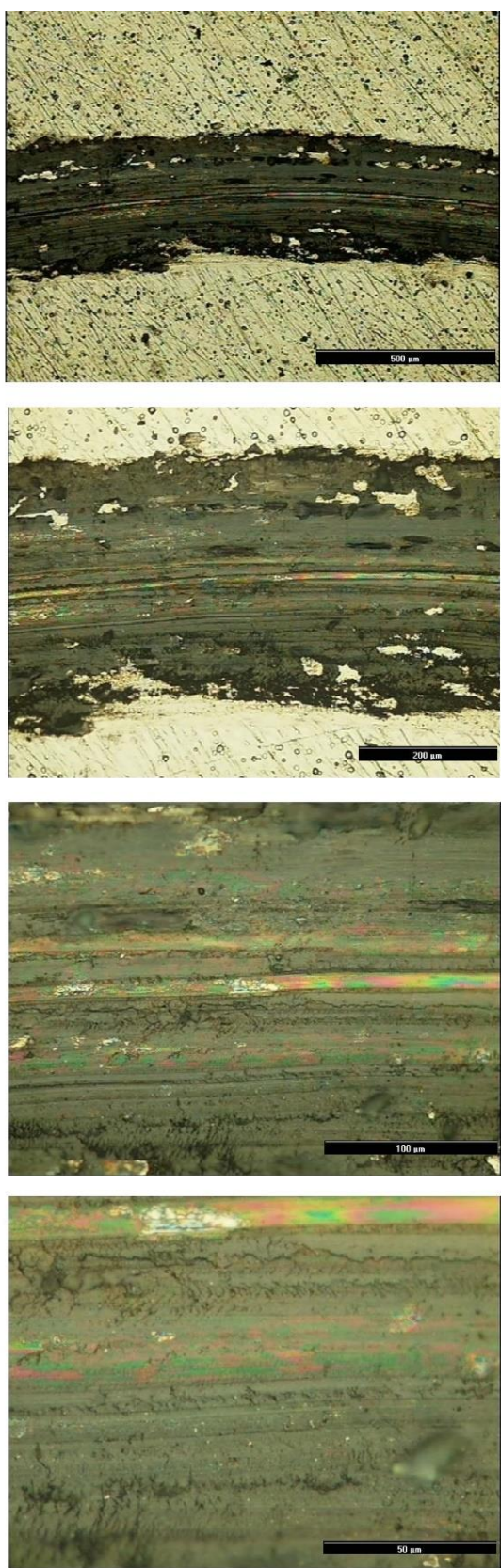

$\mathrm{Ni}-\mathrm{B} / \mathrm{TiB}_{2}$ kompozit

Şekil 9. Saf nikel ve Ni-B/TiB ${ }_{2}$ kompozit kaplamaların aşınma izi optik mikroskop görüntüleri (sırasıyla yukardan aşağıya 100, 200, 500 ve 1000 büyütme oranlarında) 
Elektrokimyasal Depolama Yöntemi ile AISI 304 Çeliği Yüzeyine Biriktirilen Ni-B/TiB 2 Kompozit Kaplamaların Kristal Yapı ve Bazı Mekanik Özelliklerinin İncelenmesi

Çizelge 4. Saf nikel ve Ni-B/TiB $\mathrm{T}_{2}$ kompozit kaplamaların aşınma analizi verileri

\begin{tabular}{|c|c|c|c|}
\hline Numune & $\begin{array}{c}\text { Aşınma iz } \\
\text { genişliği } \\
(\mathbf{w}, \mathbf{m m})\end{array}$ & $\begin{array}{c}\text { Aşınma } \\
\text { hacim } \\
\text { kaybı } \\
\left(\mathbf{V}, \mathbf{~ m m}^{3}\right)\end{array}$ & $\begin{array}{c}\text { Ortalama } \\
\text { sürtünme } \\
\text { katsayıs }\end{array}$ \\
\hline Saf nikel & $\sim 0,4$ & 0,04636 & 0,227 \\
\hline $\begin{array}{c}\mathrm{Ni}^{-} \\
\mathrm{B} / \mathrm{TiB}_{2} \\
\text { kompozit }\end{array}$ & $\sim 0,28$ & 0,01915 & 0,187 \\
\hline
\end{tabular}

\section{SONUÇLAR}

Geleneksel elektrodepolama metoduyla $\mathrm{Ni}-\mathrm{B}$ alaşım ana yapılı ve mikro boyutta $\mathrm{TiB}_{2}$ parçacıkları ile takviyeli kompozit kaplama elde edilmiş ve yine aynı metotla üretilen saf nikel ve Ni-B alaşım kaplamalar ile mukayese edilmiştir. Kronopotansiyometri grafiklerine göre elektrolite parçacıkların ilave edilmesi sabit akımda depolanan banyoda potansiyel artışına sebep olmuștur. Saf nikelin bor ile desteklenmesi ortalama kristal tane boyutunu ciddi miktarda azaltırken, takviye parçacıklar tane boyutu değerinin tekrar artış göstermesine sebep olmuştur. Elde edilen kaplamaların morfolojileri birbirinden farklı görünmekle birlikte, genel olarak pürüzsüz düzgün yüzeyli kaplamalar elde edilmiștir. $\mathrm{TiB}_{2}$ parçacıklarla takviye işlemi mikro sertlikte paslanmaz çeliğe göre $\% 225$, saf nikele göre $\% 115$ civarında artışa sebep olurken, Ni-B alaşımına kıyasla yaklaşık $\% 60$ civarında bir artışla sonuçlanmıştır. Aşınma analiz sonuçlarına göre kompozit kaplamanın saf nikele göre aşınma hacim kaybında yaklaşı $\% 50$ civarında bir azalma söz konusudur. Ayrıca, saf nikelin sürtünme katsayıs1 0,227 olarak elde edilirken, kompozit kaplamanın sürtünme katsayısı 0,187 olarak elde edilmiștir.

\section{TEŞEKKÜR}

$\mathrm{Bu}$ çalışma, Çukurova Üniversitesi Bilimsel Araştırma Projeleri birimi tarafından desteklenmiştir. (Proje ID: 12868)

\section{KAYNAKLAR}

1. Vitry, V., Francq, E., Bonin, L., 2019. Mechanical Properties of Heat-Treated Duplex Electroless Nickel Coatings. Surface Engineering, 35, 159-67.

2. Salehikahrizsangi, P., Raeissi, K., Karimzadeh, F., Calabrese, L., Patane, S., Proverbio, E., 2018. Erosion-corrosion Behavior of Highly Hydrophobic Hierarchical Nickel Coatings. Colloids and Surfaces a-Physicochemical and Engineering Aspects, 558, 446-54.

3. Tozar, A., Karahan, İ.H., 2019. Investigation of the Mechanical Properties of Ni-B/hBN Composite Coatings Electrodeposited in Presence of CTAB as the Surfactant. Material Research Express, 6(12), 12.

4. Li, B.S., Zhang, W.W., Li, D.D., Huan, Y.X., Dong, J., 2018. Microstructural, Surface and Electrochemical Properties of a Novel NiB/Ni-W-BN Duplex Composite Coating by Co-Electrodeposition. Applied Surface Science, 458, 305-318.

5. Matsui, I., Omura, N., Yamamoto T., Takigawa Y., 2018. Electrodeposition with Intermittent Addition of Trimethylamine Borane to Produce Ductile Bulk Nanocrystalline Ni-B Alloys. Surface \& Coatings Technology, 337, 411-417.

6. Mukhopadhyay, A., Barman, T.K., Sahoo, P., 2017. Effects of Heat Treatment on Tribological Behavior of Electroless Ni-B Coating at Elevated Temperatures. Surface Review Letters, 24, 22.

7. Srinivasan, K.N., Meenakshi, R., Santhi, A., Thangavelu, P.R., John, S., 2010. Studies on Development of Electroless Ni-B Bath for Corrosion Resistance and Wear Resistance Applications. Surface Engineering, 26, 153-158.

8. Hu, C., Xu, M., Zhang, J., Hu, B., Yu, G., 2019. High Corrosion Resistance of Electroless $\mathrm{Ni} / \mathrm{Ni}-\mathrm{B}$ Coating from Fluoride-free Baths on AZ31 Magnesium Alloy. Journal of Alloys and Compounds, 770, 48-57.

9. Koch, C.C., 2007. Structural Nanocrystalline Materials: an Overwiew, J. Mater. Sci. 42(5), 1403-1414. 
10. Ünal, E., Yaşar, A., Karahan, İ.H., 2019. A Review of Electrodeposited Composite Coatings with Ni-B Alloy Matrix. Materials Research Express, 6, 092004.

11. Shakoor, R.A., Kahraman, R., Waware, U.S., Wang, Y., Gao, W., 2014. Properties of Electrodeposited Ni-B- $\mathrm{Al}_{2} \mathrm{O}_{3} \quad$ Composite Coatings. Materials and Design, 64, 127-135.

12. Cho, H.J., Kim, Y.J., Erb, U., 2018. Thermal Conductivity of Copper-diamond Composite Materials Produced by Electrodeposition and the Effect of TiC Coatings on Diamond Particles. Composite Part B-Engineering, 155, 197-203.

13. Ünal, E., Karahan, İ.H., 2018. Production and Characterization of Electrodeposited Ni-B/hBN Composite Coatings. Surface \& Coatings Technology, 333, 125-137.

14.Zhang, W., Li, B., 2018, Influence of Electrodeposition Conditions on the Microstructure and Hardness of $\mathrm{Ni}-\mathrm{B} / \mathrm{SiC}$ Nanocomposite Coatings. Int. J. Electrochem. Sci., 13(4), 3486-3500.

15. Waware, U.S., Hamouda, A.M.S., Pradhan, A.K., 2018. Effect of Codeposition of Mixed Nanoparticles $\left(\mathrm{V}_{2} \mathrm{O}_{5}\right.$ and $\left.\mathrm{ZrO}_{2}\right)$ on the Structure and Properties of Ni-B Nanocomposite Coating. Journal of Alloys and Compounds, 752, 253-259.

16. Waware, U.S., Hamouda, A.M.S., Bajaj, B., Borkar, T., Pradhan, A.K., 2018. Synthesis and Characterization of Electrodeposited Ni-B$\mathrm{Tl}_{2} \mathrm{O}_{3}$ Composite Coatings. Journal of Alloys and Compounds, 769, 353-359.

17. Waware, U.S., Hamoudaa, A.M.S., Wasekar, N.P., 2018. Mechanical Properties. Thermal Stability and Corrosion Behavior of Electrodeposited Ni-B/AlN Nanocomposite Coating. Surface \& Coatings Technology, 337, 335-341.

18. Monteiro, O.R., Murugesan, S., Khabashesku, V., 2015. Electroplated Ni-B Films and Ni-B Metal Matrix Diamond Nanocomposite Coatings. Surface \& Coatings Technology, 272, 291-297.

19. Li, B., Zhang, W., 2020. Facile Synthesis and Electrochemical Properties of a Novel Ni$\mathrm{B} / \mathrm{TiC}$ Composite Coating via Ultrasonic-
Assisted Electrodeposition. UltrasonicsSonochemistry, 61, 104837.

20.Li, D., Li, B., Du, S., Zhang, W., 2019. Synthesis of a Novel Ni-B/YSZ MetalCeramic Composite Coating via Single Step Electrodeposition at Different Current Density. Ceramics International, 45, 24884-24893.

21. Krishnaveni, K., Narayanan, T.S.N.S., Seshadri, S.K., 2009. Wear resistance of Electrodeposited Ni-B and $\mathrm{Ni}-\mathrm{B}-\mathrm{Si}_{3} \mathrm{~N}_{4}$ Composite Coatings. J. Mater. Sci., 44, 433-440.

22. Ett, G., Pessine, E.J., 1999. Pulse Current Plating of $\mathrm{TiB}_{2}$ in Molten Fluoride. Electrochimica Acta, 44, 2859-2870.

23. Gyawali, G., Cho, S.H., Lee, S.W., 2013. Electrodeposition and Characterization of Ni$\mathrm{TiB}_{2}$ Composite Coatings. Metals and Materials International, 19(1), 113-118.

24. Gyawali, G., Tripathi, K., Joshi, B., Lee, S.W., 2017. Mechanical and Tribological Properties

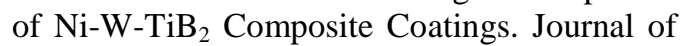
Alloys and Compounds, 721, 757-763.

25. Lee, K.B., Yoo, S.H., Kim, H.S., Won, S.O., Yang, B.J., Ahn, J.P., Choi, H.J., 2017. Nitridation-Assisted Al Infiltration for Fabricating Al Composites. Journal of Materials Science, 52, 4333-4344.

26. Huang, X., Zhaoa, Z., Zhanga, L., Yinb, C., Wu, J., 2014. Microstructure Modification and Fracture Behavior of Solidified $\mathrm{TiC}-\mathrm{TiB}_{2}$ Ceramic Prepared by Combustion Synthesis in Ultra-High Gravity Field. Journal of Asian Ceramic Societies, 2, 144-149.

27. Huang, X., Sun, S., Tu, G., Lu, S., Li, K., Zhu, X., 2017. The Microstructure of Nanocrystalline $\mathrm{TiB}_{2}$ Films Prepared by Chemical Vapor Deposition. Materials, 10(12), 1425.

28. Urszula, D.W., Agnieszka, T., Bogusław, R., 2017. Vibrational Spectroscopy of Binary Titanium Borides: First-Principles and Experimental Studies. Advances in Condensed Matter Physics, 18, 1-9.

29. Luo, P., Donga, P., Yanglib, A., Sunc, S., Zhengb, Z., Wang, H., 2015. Electrospark Deposition of $\mathrm{Al}_{2} \mathrm{O}_{3}-\mathrm{TiB}_{2} / \mathrm{Ni}$ Composite-Phase Surface Coatings on $\mathrm{Cu}-\mathrm{Cr}-\mathrm{Zr}$ Alloy 
Elektrokimyasal Depolama Yöntemi ile AISI 304 Çeliği Yüzeyine Biriktirilen Ni-B/TiB 2 Kompozit Kaplamaların Kristal Yapı ve Bazı Mekanik Özelliklerinin İncelenmesi

Electrodes. Journal of Asian Ceramic Societies, 3, 103-107.

30. Boukhoubza, I., Khenfouch, M., Achehboune, M., Mothudi, B.M., Zorkani, I., Jorio A., 2019. X-ray Diffraction Investigations of Nanostructured $\mathrm{ZnO}$ Coated with Reduced Graphene Oxide. Journal of Physics, 1292, 012011.

31. Bindu, P., Thomas, S., 2014. Estimation of Lattice Strain in ZnO Nanoparticles: X-ray Peak Profile Analysis. Journal of Theoretical and Applied Physics, 8, 123-134.

32. Saleem, M., Fang, L., Ruan, H.B., Wu, F., Huang, Q.L., Xu, C.L., Kong, C.Y., 2012. Effect of Zinc Acetate Concentration on the Structural and Optical Properties of ZnO Thin Films Deposited by Sol-Gel Method International. Journal of Physical Sciences, 7(23), 2971-2979.

33. Bilgin, V., Köse, S., Atay, F., Akyüz, I., 2005. The Effect of Substrate Temperature on the Structural and Some Physical Properties of Ultrasonically Sprayed CdS Films. Materials Chemistry and Physics 94, 103-108.

34. Khan, Z. R., Zulfequar, M., Khan, M.S., 2010. Optical and Structural Properties of Thermally Evaporated Cadmium Sulphide Thin Films on Silicon (100) Wafers. Materials Science and Engineering B, 174, 145-149.

35. Williamson, G.B., Smallman, R.C., 1956. Dislocation Densities in Some Annealed and Cold-worked Metals from Measurements on the $\mathrm{x}$-ray Debye-scherrer Spectrum. Philosophical Magazine A, Series 8, 1, 34-46.

36. Patterson, A.L., 1939. The Scherrer Formula for X-ray Particle Size Determination. Physical Rewiev, 56, 978-982.

37. Gyawali, G., Kim, H.S., Tripathi, K., Kim, T.H., 2014. Fabrication and Characterization of Electrodeposited Ni-SiC-hBN Composite Coatings. J. Mater. Sci. Technol., 30(8), 796-802.

38. Bekish, Y.N., Poznyak, S.K., Tsybulskaya, L.S., Gaevskaya, T.V., 2009. Electrodeposited Ni-B Alloy Coatings; Structure, Corrosion Resistance and Mechanical Properties. Electrochimica Acta, 55, 2223-2231.

39. Gyawali, G., Lee, S.W., 2015. Effect of SiC and $\mathrm{hBN}$ Codeposition on Microstructural and
Tribological Properties of Ni-SiC-hBN Composite Coatings. Ceramic Processing Research, 16(2), 213-217.

40. Ogihara, H., Udagawa, K., Saji, T., 2011. Effect of Boron Content and Crystalline Structure on Hardness in Electrodeposited NiB Alloy Films, Surface\&Coatings Technology. 206, 2933-2940.

41. Wang, Y., Wang, S., Shu, X., Gao, W. Lu, W., Yan, B., 2014. Preparation and Property of SolEnhanced $\mathrm{Ni}-\mathrm{B}-\mathrm{TiO}_{2} \quad$ Nano-Composite Coatings. J. of Alloys and Compounds, 617, 472-478.

42. Ağdac1, G.E., 2019. Dökme Demir-nikel Alüminat-bronz Tabakalı Kompozitin Sürtünme ve Aşınma Davranışları. Yüksek Lisans Tezi, Fen Bilimleri Enstitüsü, Eskişehir Osmangazi Üniversitesi, 82.

43. Özmen, Y., Jahanmir S., 2015. Sulu Ortamda Silisyum Nitrür Üzerindeki Nanoyapıl1 Yüzeylerin Çok Düşük Sürtünme Özellikleri. Pamukkale Üniv. Müh. Bilim. Derg., 21(8), 337-343.

44. ASTM G99-05, 2005. Standard Test Method for Wear Testing with a Pin-on-Disk Apparatus. ASTM International, West Conshohocken, PA.

45. Günen A., 2012. Nano Bor Tozu ile Yüzeyi Alaşımlandırılan Östenitik Paslanmaz Çeliğin Mekanik Özellikler ve Korozyon Davranışının Araştırılması. Doktora Tezi, Fen Bilimleri Enstitüsü, Fırat Üniversitesi, 223. 